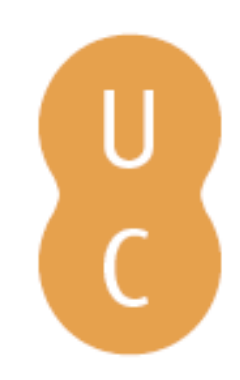

\title{
pompalina
}

\section{Quando Pã e as Ninfas convertiam os simples mortais}

Autor(es): $\quad$ Carvalho, Ana Seiça

Publicado por: Associação Portuguesa de Estudos Clássicos; Imprensa da Universidade de Coimbra

URL

persistente: URI:http://hdl.handle.net/10316.2/31752

DOI: $\quad$ DOI:http://dx.doi.org/10.14195/978-989-721-069-3_8

Accessed : $\quad$ 26-Apr-2023 14:50:48

A navegação consulta e descarregamento dos títulos inseridos nas Bibliotecas Digitais UC Digitalis, UC Pombalina e UC Impactum, pressupõem a aceitação plena e sem reservas dos Termos e Condições de Uso destas Bibliotecas Digitais, disponíveis em https://digitalis.uc.pt/pt-pt/termos.

Conforme exposto nos referidos Termos e Condições de Uso, o descarregamento de títulos de acesso restrito requer uma licença válida de autorização devendo o utilizador aceder ao(s) documento(s) a partir de um endereço de IP da instituição detentora da supramencionada licença.

Ao utilizador é apenas permitido o descarregamento para uso pessoal, pelo que o emprego do(s) título(s) descarregado(s) para outro fim, designadamente comercial, carece de autorização do respetivo autor ou editor da obra.

Na medida em que todas as obras da UC Digitalis se encontram protegidas pelo Código do Direito de Autor e Direitos Conexos e demais legislação aplicável, toda a cópia, parcial ou total, deste documento, nos casos em que é legalmente admitida, deverá conter ou fazer-se acompanhar por este aviso.

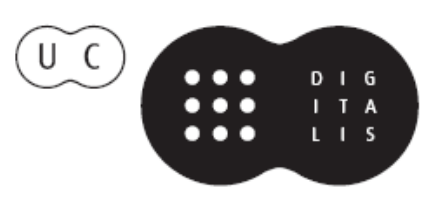




\section{Espaços e Paisagens}

\section{Antiguidade Clássica e Heranças Contemporâneas}

Vol. I Línguas e Literaturas. Grécia e Roma

Francisco de Oliveira, Cláudia Teixeira, Paula Barata Dias (coords.)

IMPRENSA DA UNIVERSIDADE DE COIMBRA 


\title{
QUANDO PÃ E AS NINFAS CONVERTIAM OS SIMPLES MORTAIS ${ }^{1}$
}

\author{
Ana Seiça Carvalho \\ Universidade de Coimbra
}

\begin{abstract}
Starting on Plato's Phaedrus and his references to Muses, Nymphs and to the Great God Pan, we take a look at the numerous nympholepts and panolepts of the Greek culture, strictly connected to the rural landscape. Nymph's power is attached to specific places like gardens (generally the perfect stage to Aphrodite's dances and full of erotic fellings from her lover dates), caverns and lands full of trees and flowers.

From caverns half-hidden in green and misteriours foliage, to secret places on the highest mountains, Nature itself is usually idyllic and rustic, used as a scenery and as inspiration - the true locus amoenus - wich catapults the soul to a divine trance state.

Socrates seems to distinguish the divine possession caused by the Muses or by Pan from de possession by Dionysos. The divine possession caused by the Muses and by Pan is associated with the influence of the space and of the divinities related to it, despite not translating as any kind of madness, instead as a hyper lucidity which grants beauty, art and eloquence sensitivity to the soul.
\end{abstract}

Keywords: bucolic landscape, nympholepsy, panolepsy.

Palavras-chave: ninfolepsia, paisagem bucólica, panolepsia.

\section{O Deus Pã e as Ninfas}

\footnotetext{
"Vinde, ó Musas, quer sejais chamadas melodiosas, graças à beleza do vosso canto, quer devido à aptidão musical do povo lígure; vinde e ajudai-me neste discurso" (Fedro 237a) ${ }^{2}$.
}

No Fedro platónico, que tomamos como testemunho para o presente trabalho (cujo tema, como sabemos, suscitou inúmeras interpretações diversas ${ }^{3}$ ), Fedro vem de junto de Lísias, com quem tinha passado toda a manhã sentado a ouvir um discurso sobre o amor. Seguindo os conselhos do seu médico, Erixímaco, Fedro pretende dar um passeio a pé para revigorar o corpo. Curioso com o

\footnotetext{
${ }^{1}$ Trabalho realizado sob a orientação da Doutora Teresa Schiappa, no Seminário de Grego do $4^{\circ}$ ano da licenciatura.

${ }^{2}$ Nas citações do Fedro usaremos a tradução de J. Ribeiro Ferreira: 1997.

${ }^{3} \mathrm{O}$ Fedro sofreu inúmeras interpretações e provocou uma série de discussões sobre a sua temática já desde a Antiguidade (vide P. Friedlander 1969: 241).
} 
discurso de Lísias e desejando ouvi-lo da boca do jovem, Sócrates decide acompanhá-lo. Descalços os dois (já era, aliás, um hábito de Sócrates) saem das muralhas e caminham ao longo do Rio Ilissos, molhando os pés na frescura da água, de acordo com a proposta de Sócrates (229a).

Depois de caminharem mais ou menos a distância de um estádio, na direcção do altar consagrado ao deus Bóreas ${ }^{4}$, sentam-se a descansar à sombra de um grande plátano (229b), onde ficam em amena conversação até passar a onda do calor. Do local, um verdadeiro locus amoenus, dá-se um quadro de grande beleza e vivacidade: o riacho fresco, a sombra oferecida pelo frondoso plátano, a brisa suave, a fragrância que se sente no ar, um aroma perfumado que se espalha, o som do coro das cigarras, a relva fofa, tudo convida ao relaxamento e ao descanso.

Longe dos moldes citadinos, a paisagem idílica, cheia de memórias mitológicas, proporciona o ambiente sugestivo que nos irá conduzir, ao longo da conversa, ao reconhecimento de uma forma especial de possessão, bakkheuein, que emana das divindades rurais. É neste contexto que Sócrates faz de Pã, filho de Hermes, e das Ninfas, filhas de Aquelôo, as fontes de inspiração dos seus discursos sobre Eros, as suas teknikoteroi...pros logous (Fedro 263d5-7).

Antes de mais, será conveniente debruçarmo-nos um pouco sobre as figuras de Pã e das Ninfas que impregnam a ambiência do Fedro.

Sabemos com segurança, através de testemunhos antigos (Pausânias 8.37.11. Píndaro Fr. 95 Snell) que, no século VI a.C., Pã era uma divindade exclusiva da Arcádia e de algumas regiões do Peloponeso. Do século $\mathrm{V}$ em diante, segundo nos conta Heródoto (6.105), a sua presença era já uma constante em todo o mundo grego, sobretudo na Ática, onde o culto terá sido introduzido após a batalha de Maratona ${ }^{5}$. A recepção da divindade na estrutura religiosa ter-se-á baseado na adaptação do culto a rituais já existentes: Pã é, por isso, recebido como deus xenos junto das Ninfas. Seis cavernas espalhadas pela Ática testemunham a devoção conjunta a Pã e às Ninfas ${ }^{6}$.

Existem variadas lendas sobre o nascimento de Pã, mas a mais completa e tradicional é talvez a do hino homérico que lhe é dedicado, que o apresenta como filho de Hermes e de uma ninfa cujo nome não nos é dito, filha de Dríope, por sua vez filho de Apolo. Outras fontes atribuem-lhe como mãe, ora Calisto (deusa da Arcádia), ora Penélope, deusa e ninfa confundida por muitos com a mulher de Ulisses ${ }^{7}$; outras ainda falam em Apolo, Cronos e mesmo Zeus

\footnotetext{
${ }^{4}$ Cf. Rosenmeyer 1962.
}

${ }^{5}$ É durante a Batalha de Maratona que se dá a epifania do deus a um embaixador ateniense, Filípides. O deus dá-lhe indicações para o êxito da batalha e o General, seguindo os seus conselhos, consegue levar os atenienses à vitória. Estes, mais tarde, construíram um santuário em honra do deus, predispondo-se a celebrar, em seu nome, sacrifícios anuais de agradecimento.

${ }^{6}$ Vide R. Parker 1996, especialmente pp. 164-166. A associação do culto de Pã às Ninfas no século $V$ gera entre os estudiosos opiniões contrárias, já que, por exemplo, o Fedro platónico não permite situá-la antes do séc. IV; A. Purvis 2003, especialmente pp. 33-63, baseando-se em estudos da famosa gruta de Vari, a cargo do ninfolepto Arquedamo de Tera, assegura que a recepção de Pã pelas Ninfas terá ocorrido somente em meados do século IV a.C., mediante a datação das peças arqueológicas aí encontradas.

${ }^{7}$ Outros autores defendiam, porém que poderia ser filho de Penélope, não tendo esta res- 
como seu pai; Teócrito (Bucólicas 1,2), numa posição à parte, descreve o deus como um ser solitário, nascido da terra ${ }^{8}$.

Embora o seu nome deva ligar-se etimologicamente ao latim pascere e pastor $^{9}$ desde o início que os testemunhos literários o associam ao pronome pas, pasa, pan já que o deus, ainda pequenino no colo do pai, fez rir todos os deuses do Olimpo - como o hino homérico, já citado, testemunha (v.47). Pã é também o representante da natureza selvagem, um deus campestre, meio homem e meio animal. Não obstante, a esta imagem tradicional de Pã - Pan aipolos ou nomios, o deus pastor - vem sobrepor-se outra, mais elaborada, que Platão divulga no Crátilo 408c-d: o filho de Hermes é "a linguagem em si ou o irmão da linguagem". Alguns autores associam ainda Pã ao pânico e ao terror, fenómeno de panoleptos: de rosto barbudo e enrugado, sempre envelhecido, queixo saliente, expressão matreira, dois cornos, de corpo peludo, pés de bode e super ágil, o deus fazia terrível uso do seu poder para tentar consumar alguns favores sexuais e, em determinadas batalhas, fazer recuar o inimigo ${ }^{10}$.

As Ninfas, por seu lado, eram divindades jovens que povoavam o campo, os bosques ou as águas, espíritos da natureza em geral e inseparáveis da paisagem. Personificavam a fecundidade e a graça e viviam a cantar e a fiar. Escolhiam normalmente como parceiros sexuais os grandes espíritos viris como Pã, Sátiros e Priapo. Às Ninfas atribuía-se o papel de oferecer hospitalidade aos viajantes e ainda os poderes adivinhatórios; o seu culto, já desde Homero (cf. Odisseia: 13.103-112 e 17.205-211), se ligava a alguns locais específicos, como rios, jardins, grutas, campos de árvores e flores.

\section{O poder encantatório das divindades rurais}

Tanto na conversa inicial como nos interlúdios entre os discursos contra e a favor de Eros, Sócrates manifesta-se influenciado pela ambiência que o envolve, não hesitando em declarar-se um "possuído das Ninfas": entra

guardado a sua mítica fidelidade a Ulisses na sua ausência (cf. Heródoto 2.145 e Luciano 7.2 (22).269).

${ }^{8}$ Para as diferentes variantes mitológicas, vide F. Càssola: 1975: 573 e P. Grimal: 1999: 345-346.

${ }^{9}$ Vide N. Jones 2004: 185; contudo, P. Chantraine não parece inclinar-se para esta hipótese: vide P. Chantraine 1968, s.u. pan.

${ }^{10}$ Vide R. Parker:1996, p.167: "Representation of wild Pan has two aspects. Fear and danger are certainly in it; but so too are liberation and desire". Na batalha de Maratona inspirou terror no exército persa, a tal ponto que recuaram, tornando os atenienses vitoriosos e crentes no deus. Contam-se ainda inúmeras histórias sobre as suas uniões amorosas: perseguia ninfas e mancebos com igual paixão devido à sua fome sexual insaciável; era de uma actividade sexual poderosa, raramente satisfeita, o que o levava a acumular uma tensão enorme e desvairada, acabando por se satisfazer sozinho nas moitas e rochedos. Zombado pelas ninfas devido à sua fealdade, embora as perseguisse e rogasse os seus favores, era repelido e elas fugiam-lhe, como a ninfa Syrinx (que se transformou em caniços, com os quais Pã construiu a sua flauta), Pítis (que se transformou em pinheiro), Eco (que constantemente se afastava, embora se continuasse a escutar a sua voz) e Selene, embora a tenha amado depois de lhe ter oferecido uma manada de bois brancos (cf. P. Grimal1999 s.u. Pã). 
em estado de enthousiasmos, é possuído no espírito por uma divindade e responsabiliza o local e as divindades inerentes pela sua "loucura". Em 238c, interrompe-se mesmo para perguntar a Fedro "Não te parece, como a $\mathrm{mim}$, que me encontro sob um fluxo divino?". Com efeito, apodera-se dele uma capacidade retórica e, se podemos dizê-lo, uma fluência poética e um à vontade pouco usuais, resultado de um delírio divino. $\mathrm{O}$ filósofo afirma mesmo encontrar-se "em perigo" - se continuar naquele local será vítima de ninfolepsia, tornar-se-á um nympholeptos (Fedro 238d/241e), um possuído das Ninfas.

O elogio da loucura, mania (Fedro 251a sqq) confirma essa faceta inusitada do Sócrates platónico, geralmente tido como um símbolo de racionalidade, bem documentada no método dialéctico. Mais invulgar se torna este retrato, se tivermos em conta a ambiguidade de atitudes que a mania, mesmo religiosa, implicava.

De facto, as formas extremas de possessão divina eram vistas como anormais e perigosas, dificilmente distinguidas da doença e da loucura; começaram inclusive a ser estudadas em tratados médicos como desordens da personalidade assimiláveis a um estado de epilepsia. No entanto, o ninfolepto não era visto como um epilético ou um louco, nem reagia excessivamente com convulsões, histeria ou delírios (como as Sibilas e as Pitonisas). Pelo contrário, era considerado alguém com especial inspiração e acentuado fervor religioso, alguém favorecido e honrado pelos deuses. O ninfolepto era catapultado a um elevado reconhecimento social pois acedia ao divino, passando do plano humano e profano ao mundo do sagrado ${ }^{11}$.

Platão aproveita, por isso, o efeito da paisagem bucólica para sugerir um tipo de possessão divina bem diferente do delírio dionisíaco, que se realiza com maior discrição e se traduz por uma expressão verbal mais elevada, dotando o ninfolepto de uma eloquência "supra-normal"12.

\section{Os cultos e os seus respectivos cenários}

Os testemunhos arqueológicos comprovam que, muitas vezes, o ninfolepto era o criador do seu próprio culto (geralmente em zonas rurais ou suburbanas) e profeta do deus que o possuía. Estes cultos privados eram realizados por escolha pessoal e não se baseavam em comemorações prescritas pela polis. Os cultos eram fundados sem qualquer intervenção governamental, e o seu carácter informal e as pequenas dimensões dos cultos individuais ${ }^{13}$ explicam a dificuldade em compreender a frequência com que se realizavam e a escassez de achados arqueológicos, epigráficos e literários.

As grutas e altares não se baseavam apenas no culto das Ninfas e de Pã. Outros ninfoleptos dedicavam a sua devoção a diferentes divindades. Pantalces,

${ }^{11}$ Sobre ninfolepsia em geral e outros paralelos antropológicos W. R. Connor 1988. Para outra bibliografia, cf. infra n.14.

${ }^{12}$ A possessão pelas Ninfas assemelha-se deste modo ao enthousiasmos provocado pelas Musas e eloquentemente representado em Íon 533d-536d.

${ }^{13}$ Cf. A. Purvis 2003, Capítulo I. 
oriundo da Tessália, tomou a seu cargo, no século IV a.C., a manutenção de uma gruta em Farsalos. À entrada da gruta terá deixado uma inscrição na qual dedicava o seu trabalho às Ninfas e, noutras inscrições, afirma que todo o seu trabalho fora aconselhado pelas deusas, a quem agradece a protecção concedida enquanto seu servidor. Dedicou os seus altares a divindades como Hermes, Asclépio, Pã, Apolo e Chíron. Artemidoro de Perge, por exemplo, construiu em Tera um altar dedicado aos Dioscuros.

Muito embora o fenómeno se centrasse sobretudo em homens, possuimos relatos de algumas mulheres ninfoleptas, como, por exemplo, Xenocracia ${ }^{14}$ que, na região do Pireu, se dedicava profundamente a honrar divindades zeladoras do bem-estar das crianças, entre elas, o Rio Cefiso, representado normalmente por um busto cornudo.

Mas um dos testemunhos de ninfoleptos que mais se destaca é o de Arquedamo, oriundo de Tera, que habitava, nos finais do século V a.C., uma gruta em Vari ${ }^{15}$, na encosta do Monte Himeto. Tratava-se, sem dúvida, de um estrangeiro, que terá iniciado um culto individual a Pã e às Ninfas na Ática, muito possivelmente por ter tido dificuldades no acesso ao culto público devido ao seu estatuto social. Não sabemos como sobrevivia mas talvez pudesse manter-se com as oferendas que os crentes deixavam nos altares.

As escavações arqueológicas da gruta de Arquedamo trouxeram à luz inúmeros artefactos, mas o pormenor mais interessante, para além dos altares consagrados a Hermes e Pã, são sobretudo as seis inscrições nas paredes da gruta, em que o seu nome se repete - bem como a constante reafirmação da sua origem estrangeira e do seu estatuto como ninfolepto, aconselhado pelas ninfas - e o auto-relevo com a sua figura.

Dado o acervo arqueológico encontrado, concluímos que as oferendas às divindades eram extremamente comuns, mas praticavam-se paralelamente inúmeros rituais, libações e inclusive sacrifícios. A manutenção de um culto, de uma gruta e dos altares requeria uma enorme dedicação e, muitas vezes, custos elevados, que nem toda a população poderia sustentar. Muitos destes cultos acabavam por sobreviver das oferendas dos fiéis, ou mesmo do pagamento de uma quantia estabelecida para garantir a frequência ao culto.

\section{Conclusões}

O Fedro configura assim uma abertura ao mundo exterior, associada a um tipo de religiosidade comum nas zonas rurais da Ática. Pã e as Ninfas, figuras centrais da obra mas pouco usuais no autor, são apresentados como os verdadeiros logopoioi do diálogo (aqueles que compõem os discursos), conduzindo os falantes e arrebatando até um Sócrates embevecido com o encanto rural (podemos, por isso, concordar em absoluto com S. Scully ao

${ }^{14}$ Vide A. Purvis 2003 15-32.

${ }_{15}$ Para um estudo mais aprofundado, vide W.R. Connor 1988: 166-174; A. Purvis 2003: 33-63; J. Larson 2001: 242-250. 
afirmar que "o Fedro é um mundo à parte"16). Talvez Sócrates se deixasse, por fim, persuadir de que, com o auxílio deste deus campestre, rude e brutal, mas sensível à música, ao amor e ao logos, seria possível criar uma simbiose entre a sua veia citadina e o deleite campestre que sentia, e assim atingir a moderação e o equilíbrio.

Este espaço bucólico, que incita às possessões divinas, tanto pode deleitar e suscitar a inspiração, como levar ao adormecimento da alma. As próprias cigarras, profetas das Musas (Fedro 262d), possuem um canto que pode ao mesmo tempo ser um estimulante mas também um veneno mágico que conduz ao otium ${ }^{17}$. Cabe-nos a nós não adormecer e estar atentos, aproveitando o auxílio da divindade sempre que ela estiver "à espreita".

\section{Bibliografia}

\section{Edições, Traduções, Comentários e Dicionários}

F. Càssola (1975), Inni Omerici. Roma.

P. Chantraine (1968), Dictionnaire étimologique de la langue grecque. Paris.

P. Grimal (31999), Dicionário de Mitologia Grega e Romana. Lisboa.

Heródote (1948) Histoires. Paris.

Platão, Íon. (1999), Introdução, tradução e notas de V. Jabouille. Lisboa.

Théocrite, Bucoliques Grecs 1. (1967), ed. e trad. de E. Legrand, Paris.

Homero, Odisseia. (2003), Homero, Odisseia. Tradução de F. Lourenço, Lisboa.

Lucian 7 (1969), with an english translation by M. D. Macleod. London.

Pindarus Pars II Fragmenta, Indices (1989), H. Maehler ed. Leipzig.

Pausanias (1998), Description de la Grèce, Livre 8, L'Arcadien. Paris.

Platon (1989), Cratyle, oeuvres complètes, tome 5, Paris.

Platão, Fedro (1997), Platão, Fedro. Introdução, tradução do grego e notas de J. Ribeiro Ferreira. Lisboa.

Plato's Phaedrus (2003), Plato's Phaedrus, A translation with notes, glossary, appendices, interpretive essay and introduction by S. Scully. Newburyport.

\section{Estudos}

W. R. Connor (1988), "Seized by the Nymphs, Nympholepsy and Symbolic Expression in Classical Greece", in W.R. Connor, Classical Antiquity, vol.7, No2. University of California 155-189.

P. Friedlander (1969), Plato III: The Dialogues. Second and Third Period (trad. inglesa de H. Meyerhoff). Princeton University Press.

\footnotetext{
${ }^{16}$ Cf. S. Scully 2003, Introduction p.7.

${ }^{17}$ Cf. C. L. Griswold ${ }^{2} 1996$ e C. Pereira 2007.
} 
C. L. Griswold (21996), Self knowledge in Plato's Phaedrus. Philadelphia.

N. Jones (2004), "Religion: Myth, Cult and the Town", in N. Jones, Rural Athens Under Democracy. Philadelphia, 181-186.

J. Larson (2001), Greek Nymphs: Myth, Cult, Lore. Oxford University Press.

R. Parker (1996), "New Gods", in Athenian Religion: a history. Oxford, 152198.

C. Pereira (2007), As Cigarras: recriação de Platão enquanto mito. Coimbra (no prelo).

A. Purvis (2003), Singular Dedications, founders and Innovators of Private Cults in Classical Greece. New York.

T. G. Rosenmeyer (1962), "Plato's Prayer to Pan (Phaedrus 279B8 - C3)", Hermes 90.1 34-44. 